\title{
Gerência de Configuração em Ambientes de Desenvolvimento de Software Orientados a Organização
}

\author{
Sávio Figueiredo, Gleison Santos, Ana Regina Rocha \\ COPPE/UFRJ - Programa de Engenharia de Sistemas e Computação \\ Caixa Postal 68511 - CEP: 21945-970 \\ Rio de Janeiro - RJ \\ savio@cos.ufrj.br, gleison@,cos.ufrj.br, darocha@,cos.ufrj.br
}

\begin{abstract}
Resumo
Ao longo do ciclo de vida de um projeto de software, uma grande quantidade de itens de informação é produzida e alterada. A Gerência de Configuração de Software surgiu da necessidade de controlar essas alterações para evitar a perda de controle do projeto de software. Este artigo apresenta uma abordagem para o processo de Gerência de Configuração de Software baseada no processo de Gerência de Configuração proposto pela norma ISO/IEC 12207 e pelo Software Engineering Body of Knowledge (SWEBOK). Além disso, a abordagem proposta também suporta as atividades de Gerência de Configuração que uma organização necessita executar para atingir o nível 2 de maturidade do Capability Maturity Model Integration (CMMI). Uma ferramenta denominada GConf foi implementada para apoiar a abordagem proposta. A ferramenta construída está inserida no contexto dos Ambientes de Desenvolvimento de Software Orientados à Organização.

Palavras-chave: Gerência de Configuração de Software, Qualidade de Software, Ambiente de Desenvolvimento de Software
\end{abstract}

\begin{abstract}
During the software project life cycle, a great amount of information items is produced and changed. The Software Configuration Management has arisen from the necessity of controlling these changes in order to avoid losing the software project control. This paper describes an approach for the Software Configuration Management Process based on the Software Configuration Management process presented in ISO/IEC 12207 and in the Software Engineering Body of Knowledge. Moreover, the approach also supports the Configuration Management activities that an organization needs to execute in order to reach the Capability Maturity Model Integration (CMMI) maturity level 2. A tool named GConf has been implemented to support this process. The implemented tool is part of the Enterprise-Oriented Software Development Environments.
\end{abstract}

Keywords: Software Configuration Management, Software Quality, Software Development Environment

\section{Introdução}

Ao longo do ciclo de vida de um projeto de software uma grande quantidade de itens de informação é produzida. Como exemplos desses itens é possível citar documentos, código fonte, dados, manuais, etc. Muitos desses itens provavelmente irão sofrer algumas modificações durante o projeto devido a diversas causas, como mudanças nos requisitos ou correção de defeitos. Para evitar a perda do controle do projeto em conseqüência das mudanças é preciso que estas mudanças sejam devidamente controladas e gerenciadas.

Assim, Gerência de Configuração de Software (GCS) pode ser definida como o controle da evolução de sistemas complexos ou, de forma mais pragmática, como a disciplina que permite manter produtos de software em evolução sob controle, e, portanto, contribuindo para satisfazer restrições de qualidade e de cronograma [4].

O processo de Gerência de Configuração de Software surgiu para evitar que se perca o controle do projeto em virtude dessa grande quantidade de itens de informação que são produzidos e podem ser alterados a qualquer instante. De um modo geral, este processo visa evitar a criação de inconsistências entre os itens. Tal processo também pode ser definido 
como sendo o aspecto do processo de gerência que foca exclusivamente em controlar as mudanças que ocorrem durante o projeto [19]. Este processo pode estar sendo executado durante todo o projeto, pois mudanças podem ocorrer a qualquer momento. áreas [4]:

Atualmente, um sistema típico de GCS busca prover serviços para apoiar as seguintes

- Gerenciar um repositório de componentes: Existe uma necessidade de armazenar os diferentes componentes de um produto de software e todas as versões de forma segura;

- Apoiar os engenheiros de software em suas atividades usuais: Os produtos da GCS tentam prover aos engenheiros os objetos certos, nos locais certos.

- Apoiar e controlar o processo: De forma geral, o controle de mudanças é parte integral de um produto da GCS e a tendência atual é estender a capacidade de apoio do processo neste aspecto.

Este artigo descreve um meio para auxiliar a execução da atividade de Gerência de Configuração de Software em um Ambiente de Desenvolvimento de Software Orientado à Organização. Com esta finalidade foi definido um processo com base nos estudos das técnicas de engenharia de software para GCS. Além disso, foi implementada uma ferramenta denominada GConf que apóia tal processo e está inserida no contexto dos Ambientes de Desenvolvimento de Software Orientados à Organização.

O conceito de Ambientes de Desenvolvimento de Software Orientados à Organização (ADSOrg) surgiu da necessidade de gerenciar o conhecimento organizacional adquirido ao longo de projetos de software. Estes ambientes apóiam a atividade de engenharia de software em uma organização, fornecendo o conhecimento acumulado e relevante para esta atividade, e dando apoio para o aprendizado organizacional em Engenharia de Software [18].

A seção seguinte discute a importância de se gerenciar a configuração de um projeto de software prezando-se sempre pela qualidade do produto final. A seção 3 apresenta o processo de gerência de configuração definido com base na literatura, na norma ISO/IEC 12207 [8], no SWEBOK (Software Engineering Body of Knowledge) [14] e no CMMI (Capability Maturity Model Integration) [3]. A seção 5 discute a abordagem proposta para a GCS, apresentando a ferramenta GConf, que apóia as várias atividades do processo de GCS definido. Finalmente, a seção 6 apresenta as considerações finais.

\section{Qualidade de Software X Gerência de Configuração}

GCS é um importante campo de pesquisa em engenharia de software, sendo adotado de forma mais ampla a cada dia [5] e podendo ser definido como uma abordagem disciplinada para gerenciar a evolução do desenvolvimento de software, práticas de manutenção e os produtos de software [2]. A GCS gerencia os artefatos do processo de desenvolvimento, controla as mudanças no software e sem seus componentes e ajuda o desenvolvimento de software [10]. GCS é uma atividade de apoio que pode ser executada ao longo de todo ciclo de vida do software, pois mudanças podem ocorrer a qualquer instante. As atividades de GCS são executadas para identificar as mudanças, controlá-las, assegurar que as mesmas sejam implementadas corretamente e reportá-las para as pessoas que possam estar interessadas [12].

Do ponto de vista da gerência do projeto, a GCS é importante porque controla a evolução e a integridade de um produto ao identificar seus elementos, gerenciar e controlar mudanças, e ao registrar e informar tais mudanças. Do ponto de vista dos desenvolvedores, tal processo facilita a implementação das atividades de mudança e desenvolvimento [14].

Este processo está fortemente relacionado à atividade de garantia da qualidade, cujo objetivo é monitorar o produto e os processos, para tentar assegurar que eles estejam em 
conformidade com os requisitos especificados e os planos estabelecidos. As atividades do processo de gerência de configuração de software auxiliam a alcançar os objetivos mencionados, sendo, portanto um elemento importante na garantia da qualidade do software.

Os processos relacionados à GCS descritos na norma ISO/IEC 12207 [8] e no SWEBOK [14] possuem basicamente as seguintes atividades: (1) Implementação do Processo; (2) Identificação da Configuração; (3) Controle da Configuração; (4) Relato da Situação; (5) Avaliação da Configuração; (6) Gerência de Liberação de Entrega.

A seção seguinte apresenta o processo de GCS definido no contexto dessa abordagem. Este processo foi baseado nas abordagens propostas pela norma ISO/IEC 12207 [8] e pelo SWEBOK [14] e suporta as atividades do nível de maturidade 2 da área de gerência de configuração do CMMI [3].

\section{Processo de Gerência de Configuração}

A abordagem proposta para o processo de GCS envolve a execução de seis atividades: (i) Planejar Gerência de Configuração; (ii) Identificar Configuração; (iii) Controlar Configuração; (iv) Relatar Situação; (v) Auditoria da Configuração, e, (vi) Gerência de Liberação e Entrega. A Figura 1 ilustra as atividades do processo proposto assim como suas sub-atividades.

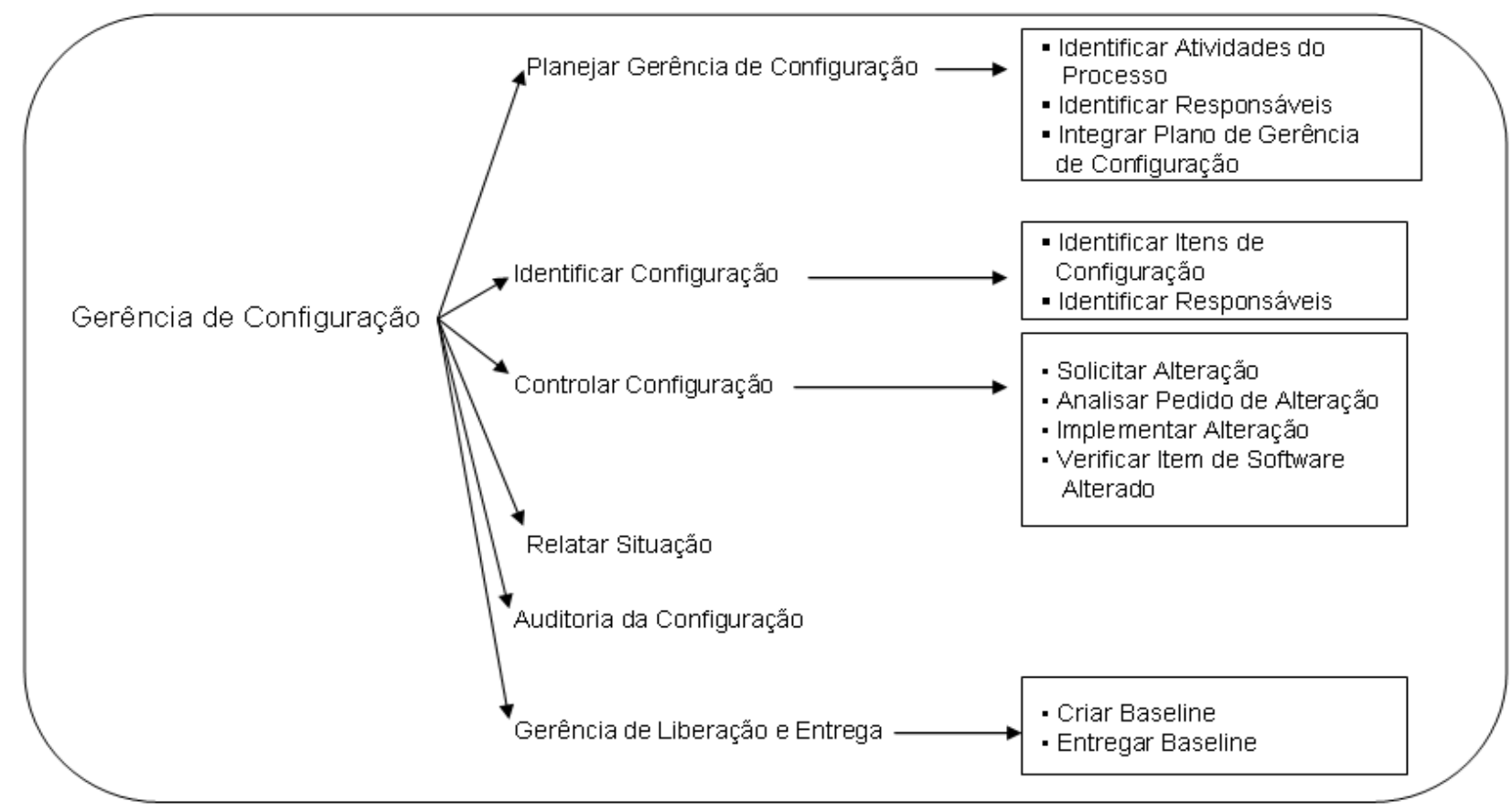

Figura 1 - Processo de Gerência de Configuração

A primeira atividade a ser executada é o planejamento da gerência de configuração. Esta atividade pode ser dividida nas seguintes sub-atividades:

- Identificar Atividades do Processo: Nesta atividade, as atividades que irão compor o processo de GCS devem ser identificadas, levando em conta as características da organização. Além disso, devem ser definidos os responsáveis pela execução de cada atividade, assim como o momento e a forma como estas atividades serão executadas e os recursos que precisarão estar disponíveis para que as mesmas possam ser realizadas [7, 9].

- Identificar Responsáveis: Ao executar esta atividade, é possível identificar o quadro de configuração, ou seja, as pessoas que serão responsáveis por avaliar, aprovando ou não, os 
pedidos de alteração e as alterações propriamente ditas.

- Integrar Plano de Gerência de Configuração: No planejamento da gerência de configuração é produzido o plano de gerência de configuração que contém as atividades relacionadas ao processo de gerência de configuração, assim como os responsáveis por estas atividades. O plano do projeto deve ser atualizado com o plano de gerência de configuração e o plano do processo de desenvolvimento deve ser atualizado com as atividades previstas para realizar a gerência de configuração.

Após ter implementado o processo de gerência de configuração, é necessário identificar a configuração, ou seja, identificar os itens de informação que devem ficar sob controle da gerência de configuração, assim como algumas informações sobre estes itens. Os itens que forem colocados sob controle da gerência de configuração terão as suas modificações ao longo do processo controladas, além de possuírem também um histórico destas alterações e todas as versões salvas. Esta atividade não ocorre apenas no início do processo pois um item de configuração pode ser identificado mesmo depois do processo de gerência de configuração já ter sido iniciado. Tal atividade é constituída das seguintes subatividades:

- Identificar Itens de Configuração: Na realização desta atividade, o gerente do projeto deve em primeiro lugar analisar todos os itens de configuração que serão produzidos ao longo do ciclo de vida do projeto e identificar aqueles que deverão ter suas modificações controladas. De um modo geral, os itens identificados devem ser os mais usados no ciclo de vida, os mais genéricos, os mais importantes para a segurança, os projetados para reutilização e os que podem ser modificados por várias pessoas ao mesmo tempo [1]. $\mathrm{O}$ gerente do projeto também deve descrever as características importantes de cada item de configuração e identificar o momento do ciclo de vida do projeto no qual cada item identificado passará a estar sob controle.

- Identificar Responsáveis: Ao executar esta atividade, o gerente do projeto é capaz de identificar os responsáveis por cada item de configuração. Estes responsáveis serão selecionados dentre os identificados no planejamento da gerência de configuração. Cada item poderá possuir diferentes responsáveis de acordo com suas características.

A atividade Controlar Configuração tem por objetivo manter o controle e o registro das mudanças realizadas nos itens de configuração ao longo do processo de desenvolvimento. Esta atividade se divide como abaixo:

- Solicitar Alteração: Esta atividade pode ser executada por qualquer membro da equipe de desenvolvimento que deseje alterar um item de configuração. Ao executá-la, o usuário deve, em primeiro lugar, identificar o item de configuração a ser alterado dentre os itens sob controle da gerência de configuração liberados para sofrer modificações. Um item pode não estar liberado para sofrer alteração, por exemplo, caso o mesmo já esteja sendo alterado por outra pessoa. Em seguida, o usuário precisa descrever o motivo pelo qual deseja modificar o item em questão assim como o impacto que esta modificação irá provocar, como por exemplo, pode ser necessário alterar outros itens após modificar este item para que os itens fiquem consistentes.

- Analisar Pedido de Alteração: Caso um item possua uma solicitação de alteração, os seus responsáveis poderão analisar o pedido de alteração e em seguida fornecer um parecer aprovando ou não a solicitação. Ao executar esta atividade, o gerente do projeto poderá analisar o pedido de alteração e os pareceres que foram emitidos pelos responsáveis por aquele item. Tendo feito isso, o gerente poderá emitir um parecer final que permita a alteração do item ou não. Além disso, o gerente também precisará indicar o responsável 
pela alteração, de modo que o solicitante e o responsável pela alteração não são necessariamente a mesma pessoa. Como conseqüência do parecer do gerente, as seguintes situações podem ocorrer:

(i) Aprovado: Se o parecer for aprovado, o responsável pela alteração deve implementá-la e, em seguida, submetê-la à análise.

(ii) Não aprovado: Caso a solicitação não tenha sido aprovada, então o estado do item volta a ser liberado para que outras pessoas possam solicitar alterações.

- Implementar Alteração: Se o pedido de alteração de um determinado item for aprovado, o responsável pela alteração poderá realizá-la. Em primeiro lugar, este desenvolvedor deve obter a última versão do item de configuração a ser alterado e então, realizar as mudanças necessárias. Tendo terminado de implementar as alterações no item, o usuário poderá submeter a alteração à análise. Além de enviar o item propriamente dito, o desenvolvedor também deverá descrever a alteração que foi realizada.

- Verificar Item de Software Alterado: Nesta atividade, os responsáveis por um item de configuração com uma alteração enviada para análise, devem obter esta alteração para que possam analisá-la. Estes responsáveis devem verificar a descrição da alteração e o item de software alterado para serem capazes de fornecer um parecer aprovando a alteração, reprovando-a ou então informando ao responsável pela alteração a necessidade de rever algumas pendências na mesma para que esta seja aprovada. Também é necessário justificar o parecer dado. O gerente, além de verificar a alteração e a descrição da alteração, deverá analisar os pareceres que foram fornecidos pelos responsáveis do item de configuração em questão. Finalmente, o gerente indicará o parecer final. Três situações diferentes podem ocorrer de acordo com o parecer do gerente do projeto:

(i) Não aprovado: Nada é feito em relação à última versão do item de configuração alterado que volta a estar liberado para que outras pessoas o modifiquem desde que tenham seu pedido de alteração aprovado.

(ii) Aprovado: É gerada uma nova versão do item de configuração em questão contendo a alteração implementada. Esta versão passa a ser a última versão deste item e o item de configuração vai para a situação de liberado.

(iii) Rever Alterações: O responsável pela alteração é notificado que deve rever alguns fatos na alteração para que a mesma seja aprovada. Após estas modificações terem sido efetuadas, o item alterado deve ser novamente enviado para análise e a atividade de verificação do item de software alterado deve ser executada novamente.

A atividade Relatar Situação tem por objetivo manter todos os envolvidos no projeto informados sobre as alterações ocorridas nos itens de configuração, ou seja, as modificações na configuração do software. Logo, informações como quem modificou um certo item, quem está modificando determinado item, quando uma modificação ocorreu, quais itens serão afetados por uma alteração, porque uma alteração foi necessária, entre outras coisas, devem ser mantidas. As pessoas que poderão ter acesso a tais informações devem possuir um acesso rápido às mesmas.

Outra atividade existente no processo é a Auditoria da Configuração. Esta atividade visa assegurar que as alterações tenham sido implementadas corretamente. Essas auditorias são conduzidas de acordo com processos bem definidos que se constituem de vários papéis e responsabilidades de auditores. Logo, cada auditoria deve ser planejada cuidadosamente. Uma auditoria pode necessitar de um certo número de indivíduos para realizar uma variedade de tarefas durante um período de tempo razoavelmente curto. 
Dois tipos de avaliação podem ser feitas: funcional e física. A avaliação funcional investiga os aspectos lógicos dos arquivos. Por outro lado, a avaliação física consiste em verificar se a configuração a ser congelada está composta da versão mais recente dos itens de configuração determinados para a fase específica do ciclo de vida e se os procedimentos e padrões foram realizados corretamente. A avaliação física é executada no fim de cada fase do ciclo de vida do software.

A última atividade é a Gerência de Liberação e Entrega. Esta atividade controla a liberação e a entrega dos produtos e da documentação de software levando em consideração as políticas da organização. Sendo assim, executando a Gerência de Liberação e Entrega é possível criar, empacotar e entregar os baselines ${ }^{1}$ para o cliente ou para outro receptor, como uma atividade de teste, por exemplo. Os baselines criados contêm apenas itens de configuração sob controle da GCS, cada baseline é devidamente documentado e está disponível para ser liberado após ter sido criado. O responsável pela execução desta atividade é o gerente do projeto e a mesma pode ser dividida em duas sub-atividades:

- Criar Baseline: Para criar um baseline, o gerente do projeto deve identificar os itens de configuração e as versões destes itens que devem fazer parte do baseline além de descrever o baseline. Também devem ser descritas as diferenças entre este baseline e os anteriores.

- Entregar Baseline: Nesta atividade, o gerente do projeto deve em primeiro lugar selecionar o baseline a ser entregue. Tendo feito isso, o gerente deve empacotar o baseline em questão e em seguida entregá-lo ao receptor.

O processo descrito não é executado de forma sequencial. A primeira atividade (Planejamento da GCS) deve ser executada durante o planejamento do projeto, as demais devem ser executadas várias vezes ao longo do desenvolvimento do projeto, sempre, por exemplo, que um desenvolvedor sentir a necessidade de alterar um item de configuração. A Tabela 1 apresenta os responsáveis por cada atividade do processo.

Tabela 1 - Responsáveis pelas atividades do processo de GCS

\begin{tabular}{|l|l|l|l|}
\hline Atividade do Processo de GCS & $\begin{array}{c}\text { Gerente do } \\
\text { Projeto }\end{array}$ & $\begin{array}{l}\text { Responsáveis } \\
\text { pelo Item }\end{array}$ & $\begin{array}{l}\text { Equipe do } \\
\text { Projeto }\end{array}$ \\
\hline Identificar Atividades do Processo & & & \\
\hline Identificar Responsáveis & & & \\
\hline Integrar Plano de CGS & & & \\
\hline Identificar Itens de Configuração & & & \\
\hline Identificar Responsáveis & & & \\
\hline Solicitar Alteração & & & \\
\hline Analisar Pedido de Alteração & & & \\
\hline Implementar Alteração & & & \\
\hline Verificar Item de Software Alterado & & & \\
\hline Relatar Situação & & & \\
\hline Auditoria da Configuração & & & \\
\hline Criar Baseline & & & \\
\hline Entregar Baseline & & & \\
\hline
\end{tabular}

\footnotetext{
${ }^{1}$ Baseline é um conjunto de itens de software formalmente designados e estabelecidos num tempo determinado durante o ciclo de vida do software [14].
} 
A Tabela 2 relaciona as atividades do processo definido com as práticas específicas do nível de maturidade 2 da área de processo Gerência de Configuração presente no CMMI [3].

Tabela 2 - Relacionamento entre o Processo Definido e as práticas específicas da área de GC do CMMI

\begin{tabular}{|c|c|c|c|c|c|c|}
\hline $\begin{array}{l}\text { Atividade do Processo } \\
\text { Prática Específica }\end{array}$ & 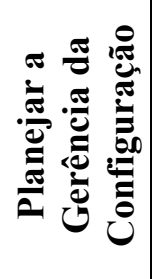 & Ũ & ن & 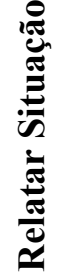 & 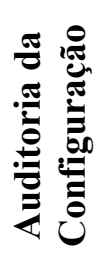 & 造 \\
\hline SP 1.1 -Identificar Itens de Configuração & & & & & & \\
\hline SP 1.2 -Estabelecer um Sistema de GC & & & & & & \\
\hline SP 1.3 - Criar ou Entregar Baselines & & & & & & \\
\hline SP 2.1 - Registrar Pedidos de Mudanças & & & & & & \\
\hline SP 2.2 - Controlar Itens de Configuração & & & & & & \\
\hline SP 3.1 - Estabelecer Registros de GC & & & & & & \\
\hline SP 3.2 - Realizar Auditorias de Configuração & & & & & & \\
\hline
\end{tabular}

A próxima seção apresenta a ferramenta GConf, que apóia as várias atividades do processo de gerência de configuração definido.

\section{A Ferramenta GConf}

Buscando-se apoiar a abordagem de GCS descrita, a ferramenta GConf foi definida e implementada. GConf apóia todas as atividades do processo de gerência de configuração proposto: identificação da configuração, controle da configuração, relato da situação, auditoria da configuração e gerência de liberação e entrega. A ferramenta é disponibilizada num Ambiente de Desenvolvimento de Software Orientado a Organização (ADSOrg).

GConf baseia-se fundamentalmente no processo definido e guia o usuário durante a realização das atividades de GCS. As principais atividades serão discutidas a seguir. Entretanto, uma visão mais detalhada do funcionamento desta ferramenta pode ser encontrada em [6]. Esta ferramenta possui três módulos de execução de acordo com o usuário que a está executando. Isto ocorre porque algumas atividades só podem ser executadas por determinados usuários (como pode ser visto na Tabela 1). As atividades de cada módulo são apresentadas abaixo:

- Módulo do Gerente do Projeto: Identificar Responsáveis, Visualizar Plano de GCS, Identificar Itens de Configuração, Identificar Responsáveis, Analisar Pedido de Alteração, Verificar Item de Software Alterado, Relatar Situação da Configuração, Auditoria da Configuração, Criar Baseline, Entregar Baseline;

- Módulo dos Responsáveis pelo Item de Configuração: Analisar Pedido de Alteração, Verificar Item de Software Alterado, Relatar Situação da Configuração;

- Módulo da Equipe do Projeto: Solicitar Alteração, Implementar Alteração, Relatar Situação da Configuração. 
A Figura 2 apresenta sua interface básica. No lado esquerdo da imagem pode-se visualizar o processo de GCS que guia a ferramenta e no lado direito da interface identifica-se a atividade que está sendo realizada pelo usuário.

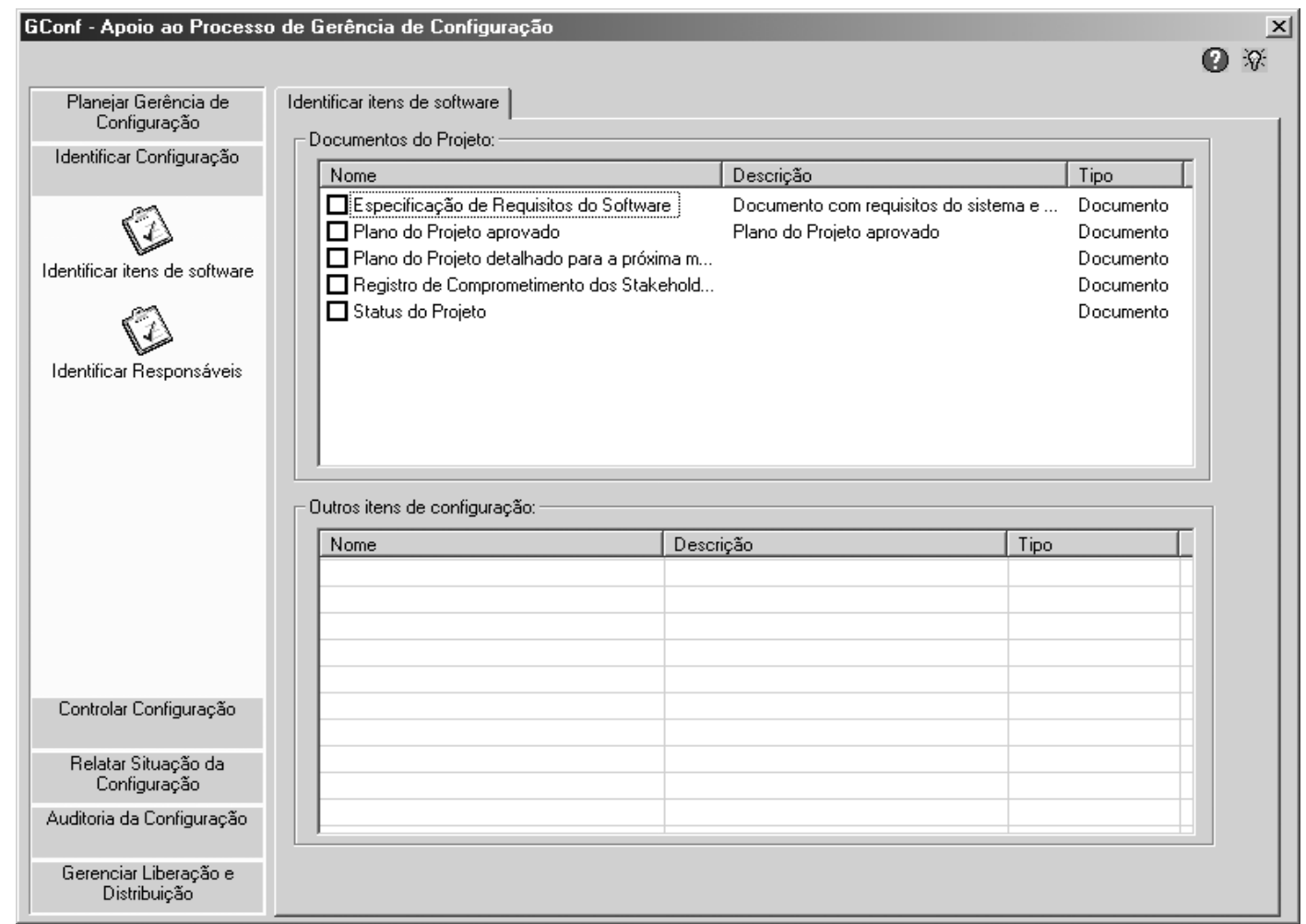

Figura 2 - Interface da Ferramenta GConf

Os ícones localizados abaixo da barra de título de todas as telas da ferramenta permitem a busca e o registro de conhecimento no que diz respeito às atividades do processo através da interação com uma ferramenta de Aquisição de Conhecimento - Acknowledge [11]. Através dessa ferramenta é permitido o registro de idéias, dúvidas, problemas encontrados, diretrizes e lições aprendidas durante a execução das atividades do processo de gerência de configuração. Após serem registradas, essas informações são, então, filtradas e empacotadas para armazenamento no repositório da organização e vinculação ao processo e atividade adequados. A partir desse momento, o novo conhecimento (agora explícito) estará acessível aos usuários da ferramenta GConf. A Figura 3 apresenta a tela de consulta de conhecimento com a descrição da atividade "Solicitar Alteração".

A Figura 2 ilustra a atividade Identificar Itens de Configuração, na qual o gerente do projeto irá identificar os itens de informação que ficarão sob controle da gerência de configuração. Na lista da parte superior da tela, são apresentados os artefatos que são produzidos pelas atividades do processo de desenvolvimento do projeto em questão. $\mathrm{O}$ gerente pode, então, selecionar os itens que desejar ou então, caso deseje incluir algum item não previsto no processo, o gerente pode incluí-lo a partir da lista na parte inferior da tela.

Um item de configuração só passa a ter suas modificações controladas pela GCS no momento em que uma primeira versão deste item seja aprovada pelo gerente do projeto. Antes disso, a manipulação do item em questão deve ser feita a partir da tela principal do ADSOrg. 


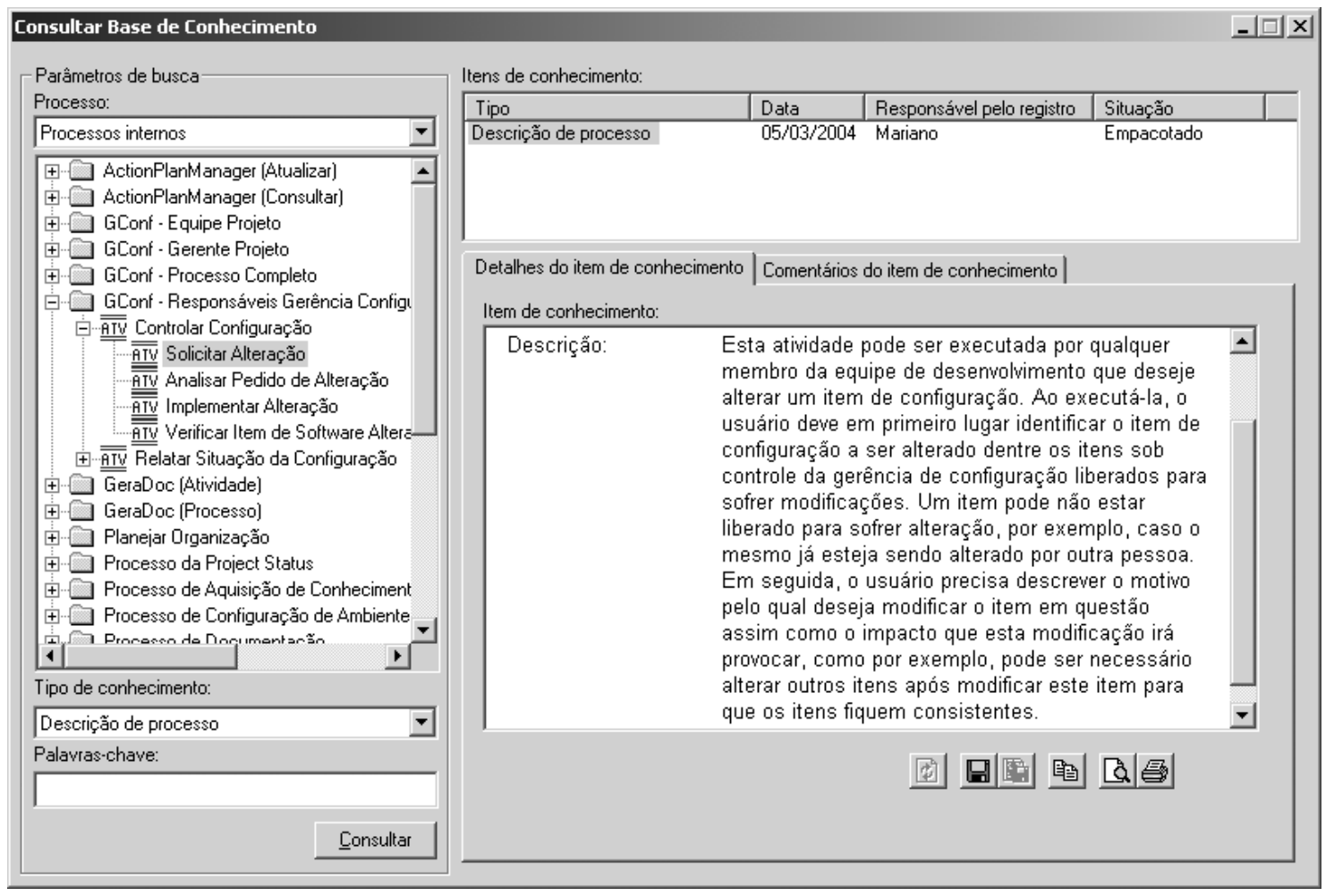

Figura 3 - Consulta de Conhecimento, através de interface com a ferramenta Acknowledge

A Figura 4 ilustra a tela apresentada quando a opção Analisar Pedido de Alteração é selecionada. Esta atividade pode ser executada pelo gerente do projeto ou então por uma pessoa que tenha sido identificada como responsável por um item de configuração com pedido de alteração pendente. A diferença entre os dois modos de execução está no fato de que o parecer dado pelo gerente do projeto é o parecer final. Este gerente utiliza os outros pareceres para poder apoiar sua decisão. Além disso, é o gerente do projeto quem seleciona o responsável pela alteração. Sendo assim, a primeira coisa a ser feita ao executar esta atividade é selecionar o item de configuração para o qual se deseja fornecer um parecer.

Este item deve ser selecionado na lista presente na parte superior da tela. Em seguida, o usuário pode analisar os outros pareceres através da caixa de texto existente em baixo da lista de itens de configuração. Nessa caixa de texto, os relatórios dos pareceres fornecidos e os detalhes da alteração que o solicitante deseja realizar podem ser visualizados na forma de uma página HTML. Tendo analisado os pareceres e a descrição do pedido, pode-se fornecer um parecer utilizando a combobox localizada abaixo da caixa de texto referida. Se o executor da ferramenta for o gerente do projeto, então também é necessário indicar quem será o responsável pela modificação a ser realizada. 


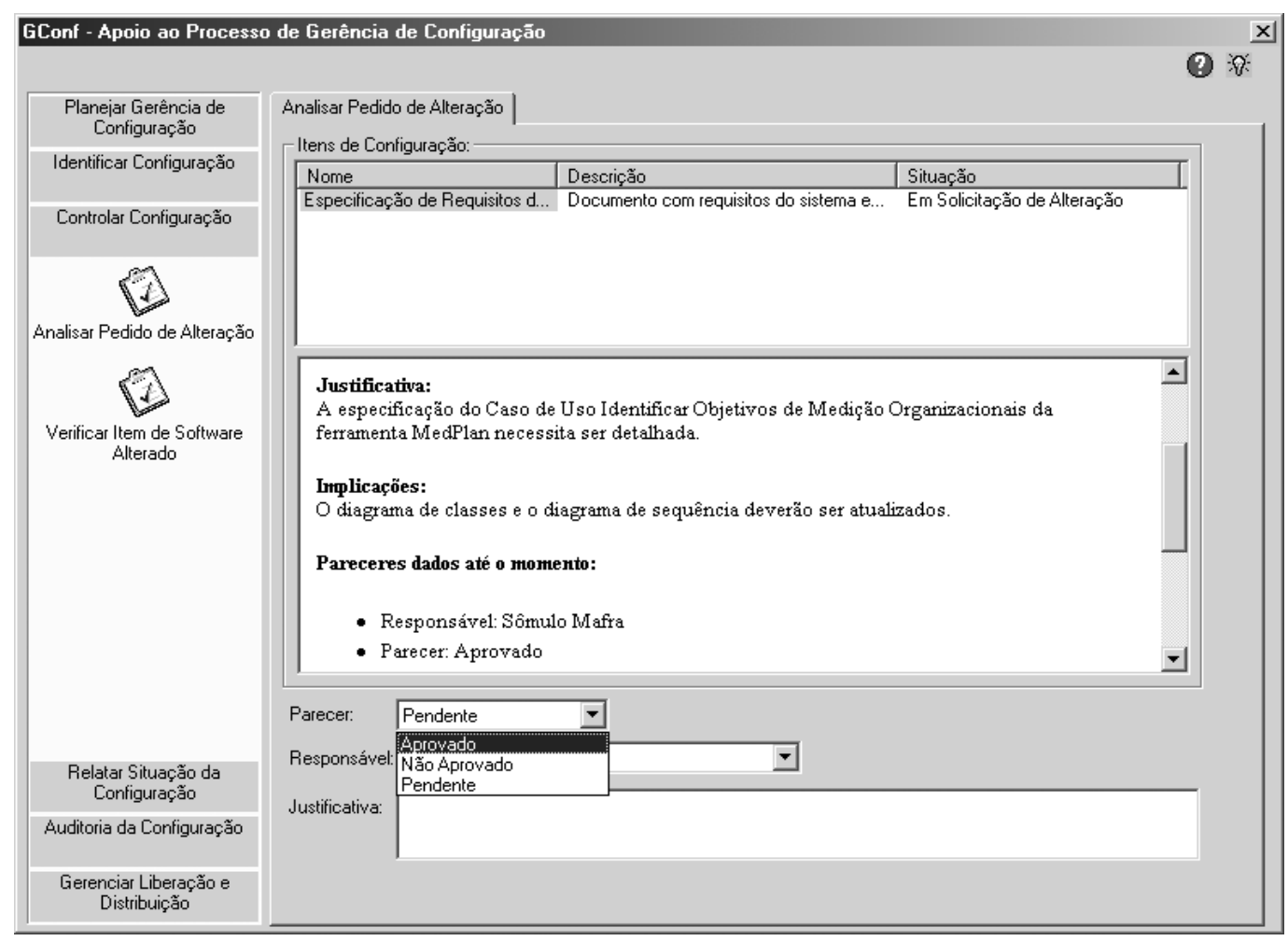

Figura 4 - Atividade Analisar Pedido de Alteração

Através da atividade Relatar Situação da Configuração, apresentada na Figura 5, é possível visualizar um relatório sobre as modificações realizadas nos itens de configuração. Para isto, basta selecionar o item desejado na lista da parte superior da tela e um relatório das alterações realizadas neste item será apresentado.

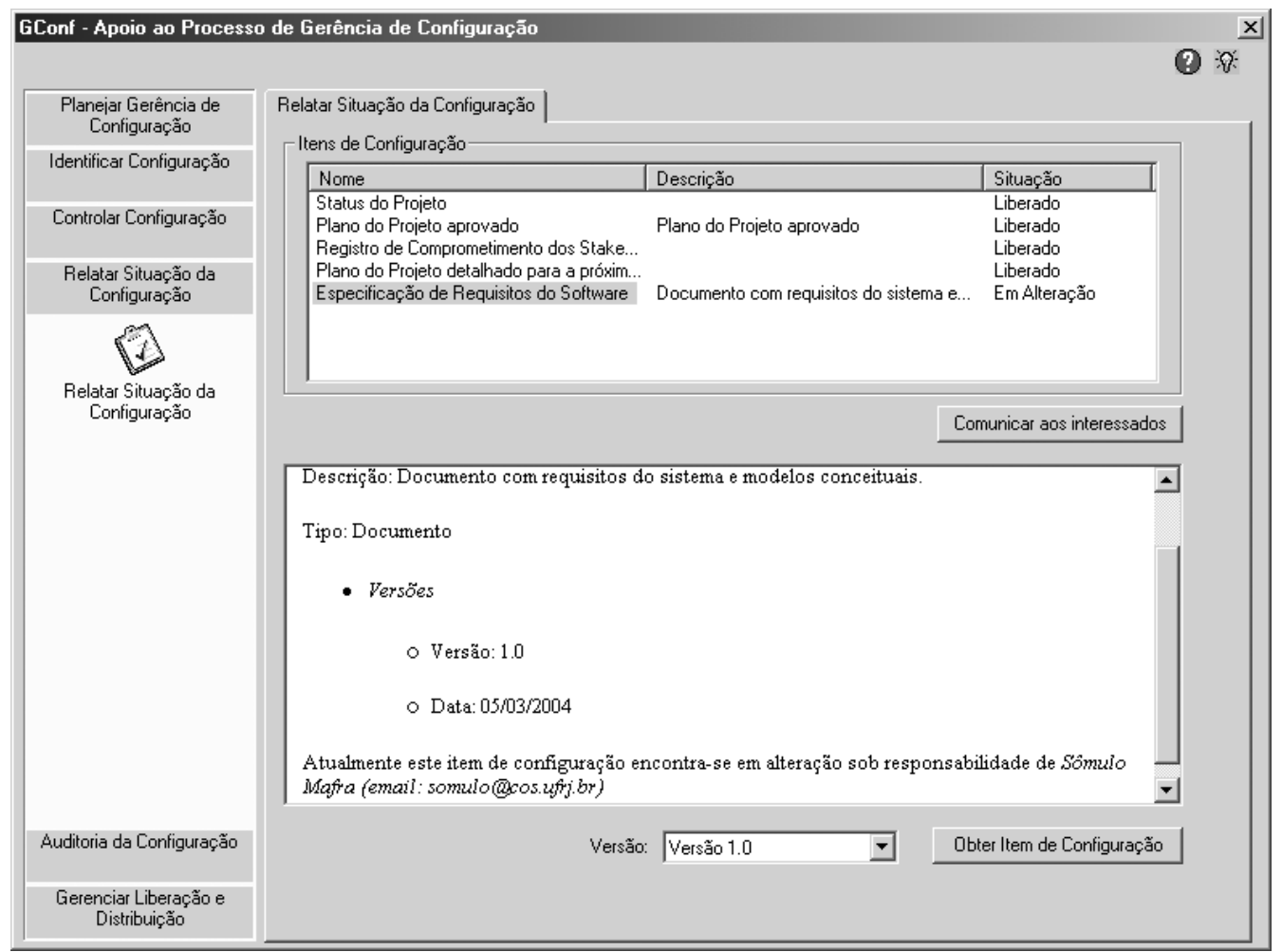

Figura 5 - Atividade Relatar Situação da Configuração 
Esta tela apresenta algumas funcionalidades adicionais. Pode-se, por exemplo, obter qualquer versão de um item de configuração ao selecionar o item na lista, a versão na combobox presente em baixo da caixa de texto e depois clicando no botão "Obter Item de Configuração". Tendo feito isto, é exibida uma tela na qual o usuário escolherá o diretório para o qual aquela versão do item de configuração selecionado será copiada. Outra funcionalidade existente é a notificação por e-mail da situação de um determinado item de configuração. Este e-mail é enviado aos "interessados pelo item", ou seja, as pessoas que executam alguma atividade que manipule $o$ item em questão. Para executar esta funcionalidade basta selecionar o item na lista e em seguida clicar no botão "Comunicar aos Interessados".

A tela apresentada na Figura 6 corresponde à atividade Entregar Baseline. Nesta atividade, o gerente do projeto seleciona, empacota e envia um baseline para o receptor desejado. O baseline a ser entregue foi criado na atividade Criar Baseline. Ao visualizar a tela, pode-se perceber na parte superior da figura a lista da qual o baseline deve ser selecionado. Esta lista contém todos os baselines do projeto. Existem duas formas de entregar o baseline selecionado: por e-mail ou colocando o baseline numa pasta onde o receptor possa pegá-lo.

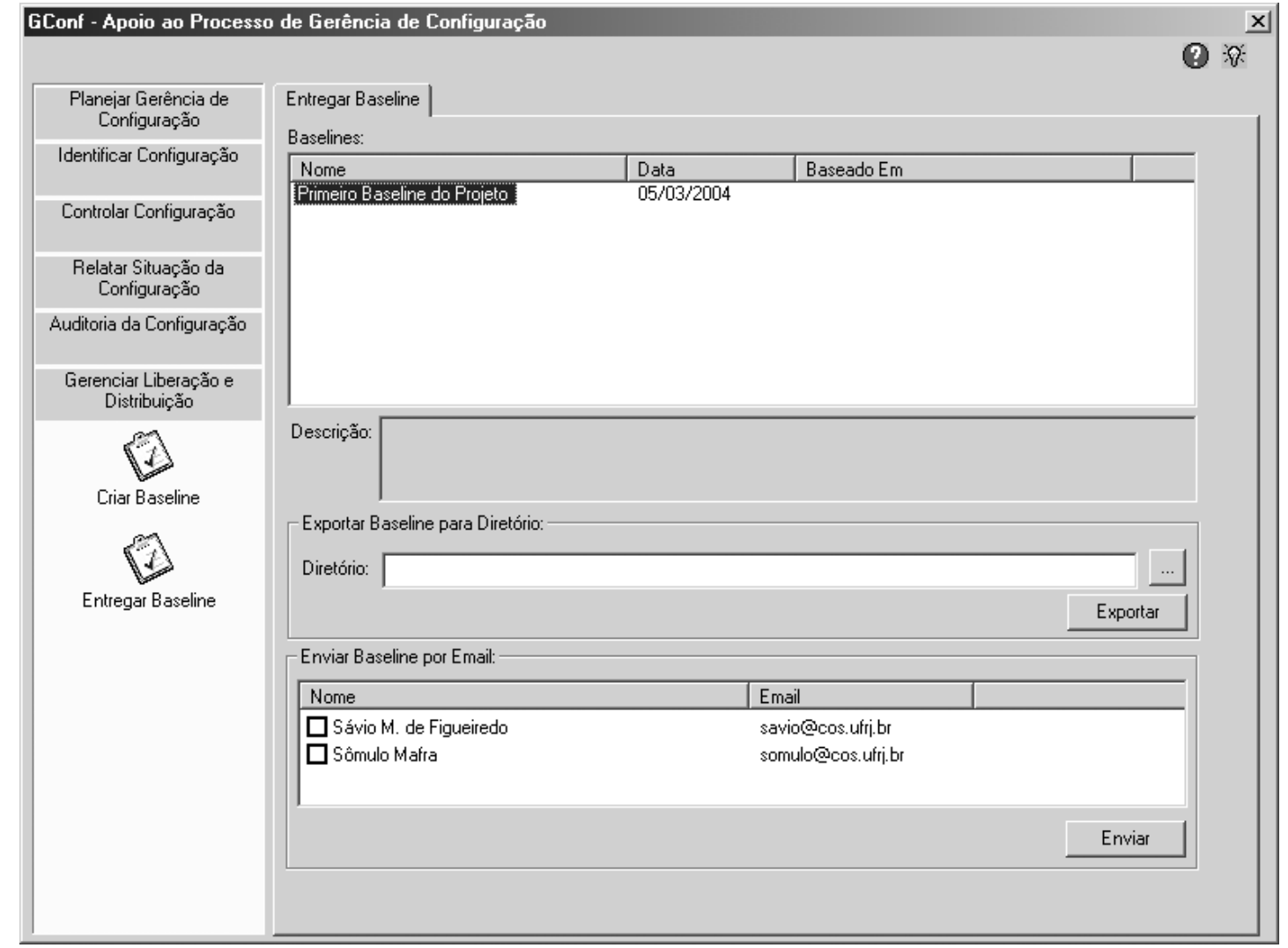

Figura 6 - Atividade Entregar Baseline

Para colocar o baseline numa pasta que o receptor tenha acesso, basta selecionar o baseline na lista, entrar com o caminho do diretório na caixa de texto "Diretório" e em seguida clicar no botão exportar. Caso o gerente prefira enviá-lo por e-mail, basta selecionar o baseline, identificar as pessoas que irão recebê-lo através da lista presente na parte inferior da tela e, então, clicar no botão "Enviar".

Em ambos os casos, o processo de empacotamento dos itens de configuração que formam o baseline é transparente ao usuário. Os arquivos referentes às versões dos itens de 
configuração pertencentes ao baseline são compactados e colocados dentro de um único arquivo. Isto é feito sem que o usuário perceba. Ao receber o baseline, a única coisa a fazer é descompactar os itens de configuração de dentro deste arquivo.

\section{GConf e Outras Ferramentas de Gerência de Configuração}

É possível destacar algumas vantagens que a ferramenta GConf possui em relação a outras ferramentas existentes no mercado. Comparando o CVS (Concurrent Versions System) [16], a ferramenta ClearCase [15] e o Visual Source Safe [15] com a GConf considerando a atividade de Controlar Configuração, percebe-se que a ferramenta GConf possui um controle muito mais intenso sobre as alterações a serem realizadas. Nas outras três ferramentas, para que um usuário realize uma modificação, basta que o item a ser alterado esteja liberado para sofrer modificações. Na GConf, por outro lado, antes de realizar uma mudança, o desenvolvedor deve realizar um pedido formal de alteração que tem de ser aprovado a fim de possibilitar a edição do item em questão. O mesmo ocorre com as alterações implementadas, que só se tornam uma nova versão do item se forem aprovadas após serem analisadas pelos responsáveis pela configuração, o que ocorre não no CVS e no Visual Source Safe.

Outra vantagem que pode ser mencionada para os usuários do ADSOrg é o fato da ferramenta estar integrada ao ambiente, portanto, os usuários não necessitam fechar o ambiente para executar a ferramenta. Todos os artefatos previstos no processo podem ser diretamente controlados a partir da ferramenta.

Também é importante citar que a ferramenta GConf permite através da interface com a ferramenta Acknowledge a consulta e registro de conhecimento no que diz respeito às atividades do processo. Deste modo, um desenvolvedor ou gerente com dúvida na forma de executar uma determinada atividade do processo de GCS pode consultar a descrição da atividade em questão ou então conhecimentos registrados por outras pessoas que já executaram esta atividade anteriormente.

\section{Conclusão}

Este artigo apresentou uma abordagem para a gerência de configuração fundamentada no conceito de Ambientes de Desenvolvimento de Software Orientados à Organização. Essa abordagem é baseada nas abordagens de gerência de configuração propostas pela ISO/IEC 12207 [8], pelo SWEBOK [14] e suporta as atividades do nível de maturidade 2 da Área de Gerência de Configuração do CMMI [3]. O processo para gerência de configuração proposto foi descrito assim como a ferramenta GConf, implementada com o intuito de apoiá-lo. Esta ferramenta está presente nos ADSOrg instanciados pela Estação TABA.

A interface entre a ferramenta GConf e a ferramenta de Aquisição de Conhecimento Acknowledge [11] permite que o conhecimento sobre gerência de configuração acumulado pela organização e relevante ao desenvolvimento de software seja consultado e que novos conhecimentos adquiridos sejam armazenados.

As perspectivas futuras para este trabalho incluem a definição e implementação de algum mecanismo que auxilie o gerente do projeto na identificação dos itens que deverão ficar sob gerência de configuração e a implementação das atividades da ferramenta que são executadas pelos desenvolvedores em um módulo WEB.

Desde o final de 2003 ADSOrg começaram a serem utilizados por 18 pequenas e médias empresas de software brasileiras. Duas grandes empresas públicas brasileiras de atuação nacional estarão iniciando sua utilização em 2004. Resultados iniciais são promissores. porém ainda é cedo para uma avaliação completa. $\mathrm{O}$ conjunto atual de usuários 
já nos permite uma avaliação das ferramentas através de um estudo experimental que está sendo planejado e será executado ao longo deste ano.

\section{Agradecimentos}

Agradecemos ao Conselho Nacional de Desenvolvimento Científico e Tecnológico (CNPq) pelo apoio financeiro ao projeto Ambientes de Desenvolvimento de Software Orientados a Organização.

\section{Referências Bibliográficas}

[1] BERLACK, H. R., 1992, "Software Configuration Management", 1ª edição. Nova York, NY, John Wiley \& Sons.

[2] BURROWS, C., S. Dart., G.W. George., 1996, Ovum Evaluates Configuration Management Tools, London, U.K, Ovum Press.

[3] CMU/SEI, Capability Maturity Model Integration (CMMI) Version 1.1 - Staged Representation, Carnegie Mellon University, Software Engineering Institute, Pittsburgh, 2002.

[4] ESTUBLIER, J., 2000, "Software Configuration Management: A Roadmap", Proceedings of the conference on The future of Software engineering, p. 279-289, June 4-11, Limerick, Ireland.

[5] ESTUBLIER, J., LEBLANG, D., CLEMM, G., CONRAD, R., TICHY, W., HOEK, A., W, D., 2002, Impact of the research community on the field of software configuration management: summary of an impact project report, ACM SIGSOFT Software Engineering Notes, v.27 n.5, September

[6] FIGUEIREDO, S, M., 2004, "Gerência de Configuração em Ambientes de Desenvolvimento de Software Orientados a Organização”, Projeto Final de Curso, UFRJ, Rio de Janeiro, RJ, Brasil.

[7] IEEE/ANSI Standard 828-1990, "Software configuration management plans", In: IEEE Software Engineering Standard Collection

[8] ISO/IEC 12207, 1995, Information Technology - Software Life-Cycle Processes.

[9] JALOTE P., 2000, "CMM in Practice: Processes for Executing Software Projects at Infosys", Addison-Wesley Publishing Company.

[10] MEI, H., ZHANG, L., YANG, F., 2001, A Software Configuration Management Model for Supporting Component-Based Software Development. Software Engineering Notes, p. 53-58, vol. 26, no. 2, ACM Press., New York, NY

[11] MONTONI, M., MIRANDA, R., ROCHA, A. R.. TRAVASSOS, G. H., "Knowledge Acquisition and Communities of Practice: An Approach to Convert Individual Knowledge into Multi-Organizational Knowledge", In: Workshop Learning Software Organization, Banff, 2004.

[12] PRESSMAN, R. S., 2001, "Software Engineering: A Practitioner's Approach", McGraw-Hill International Editions, 5th ed.

[13] ROCHA, A. R. C., MALDONADO, J. C., WEBER, K. C., 2001, "Qualidade de Software: Teoria e Prática", Prentice Hall.

[14] SCOTT, J. A., NISSE, D., 2001, "Software Configuration Management “, In: Guide to Software Engineering Body of Knowledge, Chapter 7, IEEE Computer Society Press.

[15] Site do Rational ClearCase. Disponível em http://www306.ibm.com/software/awdtools/clearcase/, verificado em 03/2004. 
[16] Site do Visual SourceSafe. Disponível em http://msdn.microsoft.com/vstudio/previous/ssafe/, verificado em 03/2004.

[17] Site do CVS. Disponível em http://www.cvshome.org/, verificado em 03/2004.

[18] VILlELA, K., OLIVEIRA, K. M., SANTOS, G., ROCHA, A. R. C., TRAVASSOS, G. H. Cordis-FBC: an Enterprise Oriented Software Development Environment In: Workshop Learning Software Organization, 2003, Luzern.

[19] WHITGIFH, D., 1991, "Methods and tools for software configuration management", Nova York, NY, John Wiley \& Sons. 